\title{
The evolution of early Spermophilus in eastern Europe and the antiquity of the Old World ground squirrels
}

\author{
Maxim V. Sinitsa and Nataliya V. Pogodina \\ Acta Palaeontologica Polonica 64 (3), 2019: 643-667 doi:https://doi.org/10.4202/app.00605.2019
}

Spermophilus is the most diverse and abundant genus of Eurasian sciurids. Even though many species have been described, the early evolution of the group is poorly understood. Here we present a review of the evolution and taxonomy of early Spermophilus, based on analysis of more than 1500 specimens from the late Pliocene and Early-Middle Pleistocene of Ukraine and European Russia, representing the most complete and continuous fossil record of the early Old World ground squirrels known to date. In addition to documenting previously unpublished specimens of Spermophilus nogaici, we describe a new species, Spermophilus praecox sp. nov., the oldest member of the genus, from the late Pliocene and Early Pleistocene (middle Villanyian to earliest Biharian) of southern Ukraine. It is intermediate in size between a somewhat smaller Spermophilus nogaici and larger Spermophilus polonicus and Spermophilus primigenius. Morphologically, the new species can be distinguished from all known Spermophilus by the retention of primitive traits including a small P3; rudimentary lingual metaloph; large metaconule and mesostyle; presence of P4-M2 endoloph; and premolariform p4 lacking a lingual metalophid. The patterns of dental evolution in eastern European early Spermophilus throughout 2.15 My indicates the existence of a single gradually evolving $S$. praecox-S. nogaici lineage characterized by a decrease of molar size but enlargement of premolars; the tendency toward high-crowned teeth with more expanded anterior and reduced posterior lobes; well-developed transverse ridges and anterostyles; reduced endolophs, anteroconules, metaconules, and mesostyles of P4-M2; molariform p4; complete $\mathrm{m} 1-\mathrm{m} 2$ metalophids; and stronger $\mathrm{m} 3$ hypoconid, hypoconulid, and entoconulid. Dental character regression suggests that Spermophilus evolved from a relatively largesized sciurid having generalized Otospermophilus-like dentition, probably an unknown North American member of stem Marmotina.

Key words: Mammalia, Rodentia, Sciuridae, Xerinae, evolution, Pliocene, Pleistocene, eastern Europe.

Maxim V. Sinitsa [sinitsamax@gmail.com], Institute of Natural Sciences and Mathematics, Ural Federal University, 19 Mira str., Ekaterinburg, 620002, Russia; and Department of Paleontology, National Museum of Natural History, 
National Academy of Sciences of Ukraine, 15 Bogdan Khmelnitsky str., Kiev, 01030, Ukraine. Nataliya V. Pogodina [N.V.Pogodina@urfu.ru], Institute of Natural Sciences and Mathematics, Ural Federal University, 19 Mira str., Ekaterinburg, 620002, Russia.

This is an open-access article distributed under the terms of the Creative Commons Attribution License (for details please see creativecommons.org), which permits unrestricted use, distribution, and reproduction in any medium, provided the original author and source are credited.

FoF Full text $(990.0 \mathrm{kB})$ 